\title{
Separated by common methods? Researchers and journalists doing expertise
}

Minna Nikunen, Päivi Korvajärvi and Tuija Koivunen

\section{Abstract}

In this article, we address emerging tensions between researchers and journalists in our research project on formations of new divisions among young adults in Finland. We focus on interviewing as a method of data gathering, and on framing as a method of presenting research results. Writing from the point of view of academic researchers, our analysis shows that journalists' and researchers' ways of doing expertise, such as techniques for asking questions, reflections on interview sensitivities, anticipated end products or the conceptual framing of the collected data, differ from each other. At the conclusion of our analysis, we reflect on the affectivity of expert work and cooperation, and on the role of affects in bringing the moral orders of different forms of expertise to the surface.

Keywords: doing expertise, research collaboration, interviewing, framing, journalists and researchers, ethnomethodology

\section{Introduction}

In this article we reflect, from the point of view of the researchers, on what happened in the research process when university researchers and freelance journalists, both with feminist orientations, cooperated on a study of (assumed) emerging inequalities among young adults. The cooperation was initiated as a requirement of the funder, the Kone Foundation, and the aim of the researchers' and journalists' joint work was to promote the dissemination of the research knowledge outside academic circles. In particular, the project aimed to influence general opinions regarding youth problems by bringing our findings into public discussion.

One of our specific aims as researchers was to make our journalist partners familiar with academic research practices, thereby improving the quality of their interpretations of the project and its accomplishments. Rather than creating a direct channel between our research and the public through 
media activities, the cooperation started at a very nitty-gritty level of doing research, namely interviewing and framing the situations of young adults. We will therefore conduct our analysis in this article in a similar vein: we will demonstrate and reflect on micro-level cooperation practices with various partners in our research process (Dean et al., 2017; Lingard et al., 2007; Matthews et al., 2017), concentrating on the cooperation between researchers and journalists.

Consequently, here we focus on the processes of interviewing and reporting, as we authors as academic researchers have comprehended and interpreted the working processes of the journalists. Both interviewing and framing are core competencies in the everyday work of academic researchers and journalists. Interviewing is a way of collecting materials for the formation of knowledge, whereas reporting is a way to turn interviews into knowledge. In broader terms we ask, how journalists and researchers 'do' their expertise, and how they frame and make sense of their observations accordingly. More specifically, we ask how mundane practices of doing expertise may cause tensions between academic research and journalist working practices. Thus we are interested in the specific parts of the diverse working cultures of the journalists and the researchers in interviewing and publishing their interpretations of the observations made. Through an analysis of some interview and reporting situations we wish to show unreflected and mundane practices of doing expertise, and discuss some aspects of the relationship between media and research.

Our argument is that combining the expertise of researchers and journalists is not simply about adding one and one to make two. Instead, a genuine cooperation is a more complex process. We analyse that complexity using the ethnomethodological concept of 'doing' social categories or identities (West and Fenstermaker, 1995; West and Zimmerman 1987). Accordingly, in our case, 'doing expertise' means inspecting the social and moral orders of interviewing people and framing the observations based on the interviews. Overall, society, economy and work currently call for new demands to combine varied expertise in innovative ways - such as between interpreters and healthcare experts (e. g. Mäntynen and Kinnunen, 2009), or in multi-professional collaborations in medical work that use digital technology and 'do being an expert' (Mondada 2007). In the field of research, cooperation with media professionals is an increasing trend, due to the growing emphasis on the social impact of research results (Väliverronen, 2016). However, there is a lack of research on the subject, especially on qualitative feminist social research.

The article is organized as follows. First, we set out the practical and conceptual contexts of the ongoing research project. Second, we consider interviewing as a way to collect materials for the formation of knowledge. In doing so we reflect on what happens when the expertise of researchers 
and journalists is integrated in research. Next, and thirdly, we turn to framing and analyse how interviews are turned to knowledge for a variety of audiences. In particular, we focus on sensitivity and the creation of balance between sensitivity and persistence in the interview situations. This illustrates the limits to our knowledge-seeking. Finally, we reflect on the affectivity of expert work and cooperation, and on the role of affects in bringing the moral orders of different forms of expertise to the surface.

2. Bringing researchers and media professionals together

In 2015, the Kone Foundation launched the research programme 'Is Finland becoming polarized?' The inspiration and model for the programme was the British study Reading the Riots, a pioneering cooperation between journalists and researchers - specifically journalists at the national newspaper The Guardian and researchers at the London School of Economics. The study was a collaborative social research enquiry that investigated and reported on the riots that took place in England in August 2011 (Reading the Riots, undated). While Reading the Riots focused on one series of events, there is not a particular event behind the Finnish programme. Instead the focus is on the current social situation, emerging social inequalities and their possible consequences. The aim of our project 'Division into two?' is to investigate inequalities among young adults, their relationships to working life and employment, and the ways in which the interviewed young adults define success and failure. The starting point of the research project is that public images and descriptions, such as policies concerning young people, employment and education, contribute to the emergence of various processes of inequality. These descriptions and definitions typically both value some groups of young people and marginalize other groups (Nikunen, 2017).

The researchers interested in the research invitation formed a team whose members had worked as colleagues for over 15 years. These researchers share theoretical perspectives on doing gender (Acker, 1992; Nikunen, 2011; Koivunen, 2010; Korvajärvi, 2011; West and Zimmerman, 1987) in organizations, work and labour. Within this group of researchers, there were hardly any of the disciplinary-based tensions or identity conflicts that can appear in interdisciplinary or otherwise heterogeneous teams (Lingard et al., 2017). In order to find interested journalists, professor Korvajärvi contacted a visiting professor in journalism, who introduced us to theree young freelance journalists. These three journalists held MA or BA degrees, and had mainly print-media experience. 
During our meeting, the researchers and journalists agreed to continue the planning of the research project together. The journalists were active in planning the funding application.

At the beginning of the study, we - researchers and journalists - had to accustom ourselves to each other's working style. We did this while searching for background material from a variety of sources. The journalists concentrated on mining interesting blogs and other media texts, whereas the researchers investigated relevant academic research. Furthermore, we conducted joint work in searching for and recruiting young people to interview. At first the idea was to find interviewees from events, clubs and social or educational services targeted at young people, relating to entrepreneurialism, international mobility, employment or activation. However, later we approached young adults also through more personal and varied connections. This was more common for the journalists. Though, we agreed that the main aim was to recruit young adults with a variety of relations to employment, and the researchers did not find this recruiting method compromising that aim.

At the beginning, the researchers and journalists conducted almost all the interviews together. The idea behind this was that the journalists could find interesting stories and people they would like to interview, and would write feature articles for newspapers or popular magazines about these stories or people. From the researchers' perspective, the purpose was to make the research process open and to familiarize the journalists with ways of doing qualitative research.

In short, the cooperation between research and the media was initiated by the funder, but we in the project team have introduced concrete forms of collaboration. In our case, three researchers and three journalists form the core group. Work within that group has been intense, especially during the phase of writing the funding application. The journalists actively contributed to the formulation of the starting points, using their experience regarding images of youth in the media. Nevertheless, it is possible that shared histories and professional identities led to the formation of two groups the researchers and the journalists - within one project. The interview phase, including the design of the questions, was shared. However, the interviews were clearly regarded as part of the research, and were designed on the researchers' terms. 


\section{Doing expertise}

It has been suggested that social scientists, including researchers on media, political economy and history, have a visible role as experts in public debate in Finland. At the same time, there is only a small number of social scientists who actively contribute to public media discussions. Journalists usually contact an expert they know and who is familiar to the public. Furthermore, journalists contact male experts more often than female experts. Thus public attention is concentrated on specific researchers, and figures of public expertise are gendered. In general, social scientists in Finland relate positively to the media. Researchers realize that public debate is a crucial part of their job, and even expect cooperation with the media to provide them with a professional advantage (Pitkänen and Niemi, 2016) However, despite the potential advantages a relationship with the media can provide, social scientists may feel that they lose control over their research when reporters or journalists insist on promoting their own views and their own frames, despite opposing messages from the researcher (e.g. Priest, 2013).

There are several options for mapping the field of our collaboration in light of academic research. In relation to our combination of expertise in interviewing and reporting, we chose the approach of 'doing expertise', and we use this approach to reveal the possible pitfalls and potentials of collaboration and research communication. This is an ethnomethodology-based idea that different cultures of expertise have different work practices, and different rules that govern these practices (Garfinkel, 1967/1984; Heritage, 1984; also Mäntynen and Kinnunen, 2009). Ethnomethodological studies on competences and being recognized as a member of an institutionalized group are closely related to the approach of doing expertise (Coulon, 1995; Ten Have, 2004: 140). A professional group, such as researchers, journalists or social workers (Morriss, 2016), is an institutionalized group in which members constantly 'do' their institutionalized rules of recognition, as well as practical and interactional rules.

By 'doing' we refer to the idea that social identities are interactional achievements. This means that one has to perform the intended identity in a way that is recognized by others in appropriate contexts (West and Fenstermaker, 1995; West and Zimmerman, 1987). In contexts of expertise, there are many valid social identities or categorizations, such as 'research interviewer' or 'journalistic interviewer', or just plain 'journalist' and 'researcher'. Members of different cultures orient to dissimilar social and moral orders - for themselves and others. They frame ongoing action and context differently than members of other groups or other cultures. Thus they have different 
ideas about the categorization of people - themselves and others - and their rights, obligations and competences. In our case, doing 'expertise' relates to situated categories such as interviewer, interviewee, researcher or journalist, in the contexts of research interviews or journalistic interviews, or of framing the interviews in the research reports. 'Doing expertise' captures the ways in which our work practices are in relation to our professions and expertise. Additionally it sheds light on different relationships with publicity and varied audiences.

One basic ethnomethodological understanding is that the rules of social order are usually invisible. They only become visible when someone breaks them. The one who breaks the norm is then held accountable for their conduct. If they cannot repair their failure, for instance by explaining it in some socially acceptable way, they are socially punished (Garfinkel, 1967/1984; Heritage, 1984; Morriss, 2016). When we are cooperating with persons who share the same norms of some social practice, such as interviewing, we all think that we are simply doing our work in the best possible way (see Morriss, 2016). ${ }^{1}$ The work and work practices have a shared meaning and shared rationale. However, members of another professional culture can break these norms and perceive them as illogical. For instance, they can frame the situation differently, orienting to a different set of rules.

\section{The ethics and practices of interviewing}

The journalists who conducted research interviews together with the researchers had basic university training in doing research. Therefore the journalists and researchers shared a common ground, and this helped our pre-interview discussions, for example regarding research ethics issues such as the sensitivity and anonymity of the interviewees. ${ }^{2}$ One sensitive issue we discussed was the possibility of labelling informants as successful or at-risk youth. We agreed that asking about this too directly would be insensitive. Previous studies have shown that it is important to interviewees that their opinions and experiences are not evaluated during the encounter (Graham et al., 2007: 1920). Our view as researchers was that addressing someone as 'socially excluded', or implying that they were such, would be tantamount to assessing their experiences. Thus the beginning of the research project became a kind of ethnomethodological experiment during which usually invisible rules surfaced (Garfinkel, 1967/1984). In what follows we focus on dissimilarities in knowledge practices and interview sensitivities.

We have found numerous similarities as well as differences in the ways journalists and researchers collect research and journalistic material. The similarities between ethnographic fieldwork and 
journalistic information-gathering formed the common ground of our collaboration. We had an agreement that the interviews we conducted were 'research interviews', not journalistic interviews. We had designed the interview structure in collaboration: researcher Nikunen wrote a draft, and then she and journalist Sallinen rewrote it together and presented it to a team meeting, where it was accepted with a few changes. We agreed that interviews would be semi-structured, and thus questions beyond the list were allowed. However, we did not discuss the researchers' ideas regarding qualitative interviewing further.

Interviewing is a main method for both journalists and researchers, but our interests in knowledge production vary. This may create tensions if one of the two groups' norms and values are understood to be under attack by another culture and therefore in need of protection (Reed, 2001; Väliverronen, 2016). This is hardly surprising, since even researchers from different disciplines or with different orientations may experience similar tensions (e.g. Lingard et al., 2007). Consequently, interview practices are affected by dissimilar rules, aims, interests, deadlines and roles. Freelance journalists must find new and original ideas to sell their work to newspapers and magazines. By contrast, for researchers continuities and 'non-events' may be as interesting as, or even more interesting than, novelties. It has been said that because journalists often work with narrow time perspectives, they prefer fast, unique, surprising and often preliminary research findings (Väliverronen, 2016: 72). Journalists are used to working at a fast pace, while researchers are more committed to the rigour of the work, even if it takes time (Newburn, 2013; Ehrenreich, 2007). Furthermore, Newburn (2013) also notes that journalists have the advantage of a can-do mentality and are not discouraged by the difficulties they encounter.

Additionally, journalistic ethics and research ethics regarding interviewing and reporting are slightly different. Various practices, aims and perceptions affect the roles of interviewer and interviewee and the relationship between them. For instance, maintaining control over the communication process is an integral part of journalistic ethics (Peters, 1995; Väliverronen, 2016). This emphasizes the journalist's positioning as a critic: a representative of the public who defends the public's need to know - for instance, against those in power. According to the guidelines for journalists issued by the Council of Mass Media (undated) in Finland, the journalist should be also critical towards information sources 'in controversial issues', since 'the source of the information may be intended for personal gain or to damage others.' However, sources' anonymity must be protected if uncovering their identity would harm them, and if it has been agreed in advance 
(Council of Mass Media, undated). The idea that some issues might be sensitive is covered under the topic of anonymity.

This is a different perspective on power relations than the one that qualitative research usually emphasizes. The relationship between interviewee and interviewer in qualitative research is usually regarded as one in which the interviewer is in a position of power. This raises the question of sensitivity and sensitive issues - that is, the possible effects of the interaction itself on the participants, especially the interviewee, rather than mere questions of anonymity - at least from a feminist perspective. However, the power relations between interviewer and interviewee are not fixed, but are negotiated situationally. Usually the researcher has power over what is discussed and how the answers are used after the encounter, and thus bears responsibility not to use that power in damaging ways (Koivunen, 2010; Oinas, 2004). It has been noted (Graham et al., 2007: 30) that interviewees are willing to deal with difficult and sensitive issues if the subject of the study is important, if they are informed beforehand that the issue will be dealt with, and if they are informed that they have the choice not to answer. Furthermore, interviewees have the expectation that any sensitive issues raised will be relevant to the research, and that the interviewer will be sensitive to any reluctance to answer.

\section{Hunting for surprises and repetitions}

It was not ethics but the simple practicalities of interviewing that were the first issue to arise during our cooperation. The differences in interview practices made visible the dissimilarity of researchers' and journalists' respective rules. For researchers, leading questions and questions that were too detailed broke the norm of allowing interviewees to tell their own story as they wished or to find answers without too much help. This was discussed in our project team meetings and in spontaneous end-of-interview reflections (see Matthews et al., 2017: 7). After a couple of initial interviews in particular, the research-journalist pairs thoroughly discussed how they felt about the interview and their collaboration. These very informal and practical reflections were later brought into our project team meetings and shared with others who had faced generally similar experiences.

The researchers also felt that the journalists were often more interested in the details and uniqueness of the interviewees' experiences during interviews than the researchers. The researchers took an 
interest in issues and features that were common among the interviewees. One interview may be unique, but for researchers who aim to conduct qualitative content analysis or discourse analysis on the data, it is still only one interview out of 40. In our analysis, even when we are closely analysing one account, its relation to the whole corpus is taken into account: either a discourse or theme is common to the interviewees, or it is an interesting exception, perhaps even a rupture in the shared common sense (Alasuutari, 1995). In other words, we planned to organize our data using crosssectional and categorical indexing (Mason, 2002).

For us as qualitative researchers who utilize a constructionist rather than a realist approach, knowledge means informants' experiences and meaning-making (Alasuutari, 1995). The knowledge and knowledge production situation - i.e. the interview - also provokes thoughts and emotions that may suggest elusive clues to follow up in the analysis. Secondly, these practical norms help us to write desirable stories. For a researcher, it is interesting to know the types of stories that people want to tell about their experiences as the authors of their own lives. Journalists aim to dig out the details of interviewees' lives in order to construct a coherent and reliable story. We discussed this difference as a group, and the journalists pointed out that the writing of narratives needs places and dates. Thus the questions that researchers consider too exhaustive are necessary for journalists to construct a narrative that might attract a general audience. In contrast to that, researchers often attempt to elicit long, solitary passages about the interviewees' experiences and thoughts for use as extracts and vivid examples in research reports.

\section{Focus and sensitivity: the limits of knowledge-seeking?}

There are three interviewees who were interviewed twice. In every case the first interview was a research interview with one researcher and one journalist, and the second was a journalistic interview with a journalist. The journalist was Paula Sallinen in two cases and Tuija Sorjanen in one, and the researchers were Minna Nikunen and Tuija Koivunen.

We - both researchers and journalists - compared the transcripts of the research and journalistic interviews with each other to pinpoint the differences in our interviewing styles. For the researchers, the journalistic interview raised some considerations. As social scientific researchers, we perceived the vocabulary that one journalist used as very psychological and even bordering on the therapeutic. Even though the interviewee was obviously familiar with the terms used, we thought that using those terms was like taking a trip to a foreign country - another discipline. The uneasiness involved 
in this experience came from established disciplinary boundaries. Even though currently we are all conducting multidisciplinary work, disciplinary boundaries still structured our reactions.

One of the topics of the journalistic interviews was depression. In our research interviews, we had no questions directly related to depression or other mental health problems. However, several interviewees discussed their depression. During the research interviews, we sometimes felt that this topic interested the journalist too much. Our study concerned young adults and their expectations of working life - we researchers felt annoyed: why should we discuss the interviewees' mental health problems more profoundly than the main topic of the research? Thus it was not surprising when this journalist wanted to interview informants with depression on her own terms.

Depression is a sensitive topic. However, this might have changed somewhat during recent decades; at any rate our young interviewees were ready to talk about it, even when we did not refer to the possibility of mental health problems. Nonetheless, the researchers were concerned that discussing such a personal topic might have consequences. Doing so could reverse the process of healing or coping, and could also negatively affect the interviewees' remediation and even retraumatize them (McCosker et al., 2001). Researcher Nikunen had previously worked on a research project on gendered violence and participated in discussions about the possibility that the interviewer might elicit a negative psychological reaction in interviewees. However, in recent years depression has become a common issue in public discussions, and thus we could anticipate that it had lost much of its taboo character and in some sense was no longer regarded as a form of mental illness.

The researchers also felt that the journalist might be too persistent: even when the informant did not want to answer a question, she would still ask it again. Additionally, she strongly insisted on detailed information about the mental state of the interviewee. Conversely, when the researchers made end-of-interview reflections on sensitive topics with the journalist, the journalist claimed that the researchers were too shy with difficult topics or lacked courage in the interview encounters. The researchers readily moved on from sensitive topics if the interviewee showed any signs of hesitation.

In our research material there is an interview passage in which the interviewee had tears in her eyes when she was speaking with the researcher. The researcher conducted this interview alone, without a journalist. 
Researcher: So you mentioned that you have had some difficult times?

Interviewee: Yeah, I'm sort of, well, I have always had seasonal affective disorder, and at that time, between secondary school and university, when I didn't really know [what would happen]. So it was like that; I had medication for depression. My parents encouraged me to go to the doctor; they said, 'You are crying all the time, so you probably should go to the doctor.'

Researcher: So it went away after you went to university, didn't it?

Interviewee: Yeah, but, ok yeah.

Researcher: This is so common nowadays. It is surprising that in our interviews, many have talked about it [depression], almost everyone, especially.

Interviewee: So it is common, then...

The researcher handled the sensitive topic and the interviewee's tears by categorizing the story as ordinary and then moving on to the next question. The idea was to avoid an issue that obviously aroused negative memories and emotions. Had there been a journalist present, she might have had the courage to ask some more about the events that had brought tears to the interviewee's eyes. Clumsy or awkward moves during an interview can imply that the researcher is not insistent enough and has problems with traumatic and shameful topics (Laitinen and Uusitalo, 2007: 321). The balance between being sensitive and being insistent is not a simple one, and involves questions of competence to help other people.

Researcher Koivunen had a somewhat similar experience when she felt that a journalist was asking follow-up questions that put unnecessary pressure on the interviewee.

Journalist: What does religion mean to you in your life?

Interviewee: Well, in fact, I believe that I wouldn't necessarily be studying at the University of Applied Sciences if I didn't have it, faith or otherwise. It has, in a way, made my life move forward.

Journalist: Tell us more about how.

Interviewee: Mm... [laughs] Well...

[Pause: seven seconds]

Journalist: Can you verbalize it?

Interviewee: Can you give me more precise questions? 
Journalist: Yes, well, how you see it, how has your faith taken you forward in your studies or supported you?

Interviewee: Yes. Well. Supported. And then again... I don't know if it can be explained. [A laugh]

[Pause: 15 seconds]

Researcher: Well, if it's difficult to tell, or I understand that it may be difficult to explain that how it -

Journalist: I understand that as well, but I'm interested in that if you are able to talk about it, it would be really interesting to hear.

Interviewee: Well...

Researcher: But it's a difficult question, so...

In the excerpt, the journalist enquires about the interviewee's religiousness. Before that, the interviewee, a young woman, had mentioned parish activities, and the journalist had asked whether the interviewee was religious. Religiousness is a question that the researcher finds too delicate and private to ask, although it is an interesting point about which she also wants to hear more. The journalist then asks about the meaning and effects of religiousness in the interviewee's life. Although the long pauses and hesitations sometimes indicate that the interviewee is thinking about the best way to answer or express oneself, the researcher who participated the interview though that in this case they reflect the interviewee finding the question difficult to answer. She is clearly very distressed because of the situation. Finally, the researcher wants to let the interviewee off the hook and move on, but the journalist repeats her question. Then the researcher begins to defend the interviewee's right not to answer the question because she, the researcher, thinks it unnecessary to pressure the interviewee any longer.

The balance between being sensitive and being insistent is not easy to achieve, for either a journalist or a researcher. However, Ehrenreich (2007: 238) suggests that researchers should be more like journalists: willing to go anywhere in pursuit of answers, when the questions take them. We agree with her, to certain limits set by research ethics and sensitivity towards interviewees that we have discussed earlier.

One reason for being interested in different issues might have been the different emphases in our research questions. From the very beginning of our research, at the design phase, the journalists sought causalities: what has affected the informants so that they are now where they are? Therefore 
being bullied at school or diagnosed with depression is interesting. However, the researchers stressed that interviewees were living 'emerging' adulthood (Arnett, 2004) rather than embodying something that had already emerged. Furthermore, a qualitative analysis of 40 interviews tells us more about the meanings and interpretations that interviewees give to success and failure than it does about their trajectories.

\section{Framings as knowledge practice}

We anticipated that differences in reporting would be inevitable, since the dissimilarities between the genres and audiences were self-evident. However, comparisons between the ways of producing knowledge also appear fruitful when we analyse differences in expertise and possible problems in cooperation. For this task we utilize the concept of framing.

The concept of framing is often used when analysing journalistic practices in news production, and in analysing the subsequent products. The term originates from the work of Erving Goffman (1974/ 1986). In social situations we ask 'what is going on here?' and the definition of the situation works as the frame. In media analysis (Fairclough, 2003: 65) 'frame' refers to the way in which reality is presented in the news - or more precisely, the frame dimension is about how reality is represented in the explanations in the text (Fairclough, 2003: 50-52; also Van Dijk, 1988: 41-48).

In the wake of Foucault (1980), it has been claimed (Alasuutari, 2010) that power and knowledge are different sides of the same coin: framing can be a form of impression management and influencing, but it is used to produce knowledge as well. Thus it is fair to say that both journalists and researchers do framing, but the ways of doing it differ to some extent. Craig Calhoun (2009: 301) argues that 'addressing public issues does not mean merely bringing social science to already clearly formulated problems. It means analysing why problems are posed in particular ways and what the implications are.' Thus framing is a problematized issue in social sciences, although it is obviously a part of any conceptualization.

When journalists write a report, this requires them to define what is happening and what the situation is. Usually, journalists draw answers from their routine, mundane knowledge, or else they turn to interest groups or experts such as researchers (Karvonen, 2000). However, it has been argued that the typical journalistic practice of framing research findings and empirical observations 
from the angle of mundane, everyday life can create tensions between journalists and researchers. This is because making a news report about a topic involves editing and linguistic choices, as well as visual methods, which frame the topic in ways about which journalists and researchers do not necessarily agree (Väliverronen, 2016: 80).

In news reports, the framing is usually done or made clear in the headline: journalistic chronology means moving from the most important issue to the details of lesser interest (Wodak, 1996: 100101). Framing often involves some level of explanation, such as 'alcohol-induced homicide' or 'misogyny-inspired femicide'. In that sense, some framings can be called feminist - the categorization of the incident is based on feminist research or activism, or comes from experts who participate in the struggle over definitions, often against anti-feminist actors (Byerly, 1999).

The journalists Paula Sallinen and Tuija Sorjanen conducted three journalistic interviews after the research interviews - two related to depression, and one focusing on life after a sports career - and Paula began her report based on one of these interviews in the following manner:

Not only male basement-dwellers live in their childhood homes: young women also isolate themselves socially within their homes - as happened to Päivi.

Twenty-seven-year-old Päivi isolated herself in her home for three years during her 20s. A fear of social situations and bullying at school explains many young people's withdrawal into their own homes.

The definition of the situation in this case was the social exclusion of young people. Paula used the term 'hikikomori' to describe those who retreat from face-to-face interactions and rely instead on the extensive use of information technology. The framing offered an explanation for this phenomenon: some young people are afraid of social situations, face-to-face interaction and bullying at school.

The explanation connects the text with other media texts, namely on social withdrawal and its connectedness to information technology. There is also something novel, namely the word 'hikikomori' (Saito, 2013; Furlong, 2008). It is a word that young people, mainly men, use in reference to themselves. Another and more popular way of framing the story would have been to use the term 'marginalization' that treats the problem as a question of school dropouts and 
unemployment which is seen as concerning mainly young men in Finland (Myrskylä 2011). Thus there are traces of feminist framing, which also emerges in the headline 'Not only male basementdwellers live in their childhood homes' - policy and media attention should not be restricted to boys' and men's problems.

It has been suggested that researchers use attractive frames to promote their research activities (Priest, 2013; Väliverronen, 2016). This means, for instance, that findings and proposed findings are linked to some social problem that is currently considered a vital topic. This is one side of the coin impression management and influencing; the other side is the quest for knowledge (Alasuutari, 2010). However, we are not saying that the divide between impression management and influencing is either/or; rather, impressions and knowledge are usually presented as being more in-between. Indeed, social phenomena are too vast to inspect without a lens, theoretical framing and focus. Furthermore, a frame that relates the research to current concerns is vital for social and critical research. However, framing is a more time-consuming process for researchers than for journalists. Typically, a journalist takes phenomena or definitions from public discussions, e.g. what the hot topic is today, and then communicates with other media, whereas a researcher turns to the literature for what has been previously written on the topic.

The researchers in our project use an intersectionally (Crenshaw, 1989) inspired feminist framing, the premise of which is that gender and social class are intertwined with each other in various social doings, often producing divisions and inequalities. The social scientific literature notes that young adults are not a monolithic category of people. Instead, gender, ethnicity and social background affect young people's aspirations and choices (e.g. Tolonen, 2005). The researchers have revealed that analysing gender alone is insufficient for the purposes of this project. However, they have also specified that it is not in our interest to inspect all differences, such as regional differences or (dis)ability. The focus on certain differences is partly practical - not everything can be included and partly due to theoretical positioning.

In addition to theoretical and conceptual framing, we do empirical framing. In this research project we are using all 40 of the interviews we have conducted. The framings will take place after the analysis has been conducted, and will hopefully then be novel and interesting. In journalists' work, one can be 'picky' and decide that some interviewees do not provide good material for an interesting article - for example, with regard to newsworthiness, news value or novelty - or material that would be easy to sell to magazines or newspapers. Also the researchers may focus on 
some features that stand out and do not occur in all of the interviews and extracts chosen, but these choices are contextualized in relation to the whole corpus. The different pace of writing and publishing is involved: journalists must write the article and do the framing in a few days, as they do not have time to interview 39 other people or dwell on the literature for three months. In journalism, practical knowledge must already be available, and definitions must be created almost instantly (also Ehrenreich, 2007).

Journalist Tuija Sorjanen chose to interview a former athlete, and this interviewee's name and picture were used in the piece - unlike in Paula Sallinen's piece about depression, where the interviewee used a pseudonym and no picture was included. The topic was not as sensitive as that of depression, and the interviewee was comfortable appearing under her own name in the pages of a weekly Finnish magazine. We had asked the interviewee to be our informant because she was an active member in a start-up entrepreneurs' club. We were interested in finding people who fit the public's and government's ideals of employability (who are seen as 'active') and those who are seen as vulnerable, for example as targets of the 'youth guarantee' whereby local and national government promise to take at-risk youth into education, employment or activation. However, the frame that Tuija Sorjanen used was that the interviewee was a former athlete rather than a start-up entrepreneur, and she also used features related to that categorization, such as the interviewee's being a perfectionist and the difficulties she faced after an active sports career. The features that differentiated this interviewee from our other interviewees comprised the frame.

In terms of framing, the journalists suggested analyses that their readers would obviously at least partly know or recognize from popular culture ('hikikomori'), or would know from their own experience (depression), or would be able to identify in terms of past success and perhaps current failure. All these framings were individual-centred, and it is worth noting that they were also not directly related to the project's research questions.

\section{Individual and shared knowledge production}

Work in academia, especially research work, has moved towards a project-oriented work model, along with larger transformations in working life. Such research projects vary in length, size and form, and practically all of them are funded by external sources. Therefore, external funding bodies are increasingly setting the boundaries for new collaborative forms of research work, as did the research partners in our case. This requires researchers to adopt new forms of collaboration within 
and outside academia. Research and researchers are encouraged to cross the lines between disciplines, and also to cooperate with experts outside academia. The results of such collaborations should therefore be presented as extensively as possible, using social media in addition to more traditional publishing channels. Hence, fluent social and communication skills are more valuable for researchers than ever.

We were also eager for mutual learning and to combine the diverse expertise of the researchers and journalists to create something new, perhaps even bold. Our multi-professional cooperation on the research project started with great enthusiasm. Indeed, in this sense the beginning was successful, and the researchers benefitted a great deal from the journalists' contacts as well as their blogging knowhow. However, when the research moved to the phase of the core practices of the researchers and journalists, it seemed that each group stuck to its particular way of doing expertise. The different styles of interviewing could make the interview situations uncomfortable for the researchers, whereas in the eyes of the journalists the researchers' style in interview situations appeared too reserved.

Furthermore, the aim of attracting readers of newspapers or feature magazines separated the journalists from the framings of the researchers. This was a paradox in our case, since one of the aims of the collaboration was to deliver research results to a wider audience that would not read academic articles. Thus the professional boundaries appeared to be rigid. In short, it was possible to break down boundaries during the design process of the study. However, during the conducting of the research, the different working cultures turned out to show their power. It was possible to lose some boundaries when planning the project and contacting key interlocutors and interviewees, but in the core practices, at least at the beginning of the study, bumps began to appear in the road of cooperation.

Framing also revealed dissimilar ways of thinking between researchers and journalists: a relationship with knowledge as facts on the one hand, and with knowledge as understanding people's lives on the other hand. Our perception as researchers was that the journalists wanted to provide facts and then draw on them to create a good and sensitive reading experience, whereas we researchers wanted more to provide ideas that would link individual experiences to broader social orders. However, journalists and researchers alike wanted to publish texts offering views that were non-obvious. In that sense our aims were the same: to affect the readers somehow. At the same time, the journalists took a closer and perhaps more consciously emotional orientation to their 
potential readers, whereas the researchers took a cooler and remoter orientation - which of course is itself an emotional orientation too. One of the questions for future research is to ask what kinds of emotion researchers should or can use when aiming for social and political influence based on their research.

Indeed, we suggest that, in addition to communicative skills, the significance of affects in doing expertise is another new insight that our study provides. Doing expertise by relying on certain social and moral orders affects others in close encounters: colleagues, team members, interviewees, and we ourselves were affected. The doings of others are usually felt as understandable, but sometimes tensions arise. Expertise and its rules, especially ethical rules, can also direct experts' attention to particular actors and foster sensitivity towards their affective reactions, ignoring those of others. Questions of identity, belonging, respect, inclusion and exclusion are felt more or less consciously, before they become targets of analysis. Tacit knowledge often surfaces as the consequence of feelings or moods in different assemblages, and in different encounters. This article provides a story about the affects felt by the researchers. An obvious task for the future is to co-write with the journalists an analysis of the ways in which the latter were affected, according to their own interpretations.

After acknowledging the part affects play in professional interactions and expert work, including in relation to interviewees, the evident next step was to turn our attention to the ways our interviewees were affected in general. Similarly, their experiences, identities, respectability, inclusions and exclusions were shaped by various encounters: with significant others, and with material artefacts such as media. These ways informed us as researchers about the prevailing and complex atmosphere, social mood or frame within which young adults were reflecting on their future. This in turn made us more sensitive to the need to understand the formation of intersectional inequalities as questions of unspeakable phenomena that frame our thoughts and activities.

\section{References}

Acker J (1992) Gendering organizational theory. In: Mills AJ and Tancred P (eds) Gendering Organizational Analysis. Newbury Park: Sage, pp.248-260. 
Alasuutari P (1995) Researching Culture: Qualitative Method and Cultural Studies. London: Sage.

Alasuutari P (2010) The nominalist turn in theorizing power. European Journal of Cultural Studies 13(4): 403-417.

Arnett JJ (2004) Emerging Adulthood: The Winding Road from the Late Teens Through the Twenties. New York: Oxford University Press.

Byerly CM (1999) News, feminism and the dialectics of gender relations. In: Mayers M (ed) Mediated Women: Representations in Popular Culture. New York, NY: Hampton Press, pp.383404.

Calhoun C (2009) Social science for public knowledge. In: Eliasson S and Kalleberg R (eds) Academics as Public Intellectuals. London: Palgrave, pp.299-317.

Coulon A (1995) Ethnomethodology. Thousand Oaks, CA: Sage.

Council of Mass Media (undated) Guidelines for journalists. Available at: http://www.jsn.fi/en/guidelines_for_journalists/ (accessed 2 January 2017).

Crenshaw K (1989) Demarginalizing the intersection of race and sex: a black feminist critique of antidiscrimination doctrine, feminist theory and antiracist politics. University of Chicago Legal Forum 1989(1): Art. 8.

Dean J, Furness P, Verrier D, Lennon H, Bennett C and Spencer S (2017) Desert island data: an investigation into researcher positionality. Qualitative Research. Epub ahead of print 22 June 2017. DOI: $10.1177 / 1468794117714612$.

Ehrenreich B (2007) A journalist's plea. In: Clawson D, Zussman R, Misra J, Gerstel N, Stokes R, Anderton DL and Burawoy M (eds) Public Sociology: Fifteen Eminent Sociologists Debate Politics and the Profession in the Twenty-first Century. Berkeley, CA: University of California Press, pp.231-238.

Fairclough N (2003) Analysing Discourse: Textual Analysis For Social Research. London: Routledge. 
Foucault M (1980) Power/Knowledge: Selected Interviews and Other Writings, 1972-1977. New York, NY: Pantheon Books.

Furlong A (2008) The Japanese hikikomori phenomenon: acute social withdrawal among young people. The Sociological Review 56(2) 309-325.

Garfinkel H (1967/1984) Studies in Ethnomethodology. Cambridge: Polity Press.

Goffman E (1974/1986) Frame Analysis: An Essay on the Organization of Experience. Boston, MA: Northeastern University Press.

Graham J, Grewal I and Lewis J (2007) Ethics in Social Research: The Views of Research Participants. London: National Centre for Social Research Unit. Available at: https://www.gov.uk/government/uploads/system/uploads/attachment_data/file/497221/ethics_partic ipants_tcm6-5783.pdf (accessed 6 November 2017).

Heritage J (1984) Garfinkel and Ethnomethodology. Cambridge: Polity Press.

Karvonen E (2000) Tulkintakehys ja kehystäminen [Frame and framing]. Tiedotustutkimus 23(2): $78-84$.

Koivunen T (2010) Practicing power and gender in the field. Learning from interview refusals. Journal of Contemporary Ethnography, 39:6, 682-708.

Korvajärvi P (2011) Practicing gender neutrality in organizations. In: Jeanes E L, Knights D and Martin PY (eds) Handbook of Gender, Work and Organization. Chichester: John Viley 231-243.

Laitinen M and Uusitalo T (2007) Sensitiivisen haastattelututkimuksen eettiset haasteet [Ethical challenges in sensitive interview research]. Janus 15(4): 316-332.

Lingard L, Schryer CF, Spafford MM and Campbell SL (2007) Negotiating the politics of identity in an interdisciplinary research team. Qualitative Research 7(4): 501-519. 
Mäntynen A and Kinnunen T (2009) Towards a collaboration between professionals. In: Dörte A and Pöllabauer S (eds) Spürst Du, wie der Bauch rauf-runter? Fachdolmetschen im Gesundheitsbereich. Munich: Meidenbauer, pp.115-138.

Mason J (2002) Qualitative Researching, Second Edition. London: Sage.

Matthews P, Rutherford R, Connelly S, Richardson L, Durose C and Vanderhoven D (2017) Everyday stories of impact: interpreting knowledge exchange in the contemporary university. (Forthcoming/Available Online), Evidence and Policy.

McCosker H, Barnard A and Gerber R (2001) Undertaking sensitive research: issues and strategies for meeting the safety needs of all participants. Forum Qualitative Sozialforschung/Forum: Qualitative Social Research 2(1): Art. 22.

Mondada L (2007) Operating together through videoconference: members' procedures for accomplishing a common space of action. In: Hester S and Francis D (eds) Orders of Ordinary Action: Respecifying Sociological Knowledge - Directions in Ethnomethodology and Conversation Analysis. Abingdon: Routledge, pp.51-68.

Morriss L (2016) Dirty secrets and being 'strange': using ethnomethodology to move beyond familiarity. Qualitative Research 16(5): 526-540.

Myrskylä, Pekka 2011: Nuoret työmarkkinoiden ja opiskelun ulkopuolella [Young people out of labour market and education]. Publications of the Ministry of Economic Affairs and Employment. Helsinki: Ministry of Economic Affairs and Employment.

National Advisory Board on Research Ethics (2009) Ethical principles of research in the humanities and social and behavioural sciences and proposals for ethical review. http://www.tenk.fi/sites/tenk.fi/files/ethicalprinciples.pdf (accessed 16 May 2018).

Newburn, T (2013) Combining journalism with academia: how to read a riot. Available at: http://eprints.lse.ac.uk/48460/ (accessed 5 January 2016). 
Nikunen M (2011) Murder-Suicide in the News - doing the routine and the drama. European Journal of Cultural Studies 14(1): 81-101.

Nikunen M (2017) Young people, future hopes and concerns in Finland and the European Union: classed and gendered expectations in policy documents. Journal of Youth Studies 20(6): 661-676.

Oinas E (2004) Haastattelu: kokemuksia, kohtaamisia, kerrontaa [Interview: experiences, encounters, narratives]. In: Liljeström M (ed) Feministinen tietäminen: Keskustelua metodologiasta. Tampere: Vastapaino, pp.209-227.

Peters HP (1995) The interaction of journalists and scientific experts: co-operation and conflict between two professional cultures. Media Culture \& Society 17(1): 31-48.

Pitkänen V and Niemi MK (2016) Hallitsematon ja houkutteleva media: Yhteiskuntatieteilijöiden näkemyksiä julkisesta asiantuntijuudesta [Uncontrollable yet tempting: how Finnish social scientists see their role as experts in the media]. Yhteiskuntapolitiikka 81(1): 5-16.

Priest S (2013) Critical science literacy: what citizens and journalists need to know to make sense of science. Bulletin of Science, Technology and Society 33(5-6): 138-145.

Reading the Riots (undated) Investigating England's summer of disorder. Available at: http://eprints.1se.ac.uk/46297/1/Reading\%20the\%20riots\%28published\%29.pdf (accessed 6 February 2017).

Reed R (2001) (Un-)professional discourse? Journalists' and scientists' stories about science in the media. Journalism 2(3): 279-298.

Saito T (2013) Hikikomori: Adolescence without End. Minneapolis, MN: University of Minnesota Press.

Ten Have P (2004) Ethnomethodology. In: Seale C, Gobo G, Gubrium J and Silverman D (eds) Qualitative Research Practice. London: Sage, pp.139-153.

Tolonen T (2005) Locality and gendered capital of working-class youth. Young: Nordic Journal of Youth Research 13(4): 343-361. 
Väliverronen E (2016) Julkinen tiede [Public Science]. Tampere: Vastapaino.

Van Dijk TA (1988) News as Discourse. Mahwah, NJ: Lawrence Erlbaum Associates.

West C and Fenstermaker S (1995) Doing difference. Gender \& Society 9(1): 8-37.

West C and Zimmerman D (1987) Doing gender. Gender \& Society 1(2): 125-151.

Wodak R (1996) Disorders of Discourse. London and New York, NY: Longman.

\footnotetext{
${ }^{1}$ Morriss (2016: 529-530) noticed that in interviews with interviewees with whom she shared a professional identity, the stories told seemed to show the 'natural' order of things. She writes about 'doing being' a social worker.

${ }^{2}$ Currently in Finland, the researchers in social sciences must submit their research plan to ethical review by the ethics committee of the governing institution when the research topic is sensitive - exposing the research subjects to potentially harmful stimuli, relating for instance to violence or pornography or can cause long-term mental harm - or when people with diminished agency or underage children are informants. Also research that can signify a security risk for the informants, requires a review. In some other research fields, such as medicine, the permission is always required since physical integrity is essential. (National Advisory Board on Research Ethics 2009).
} 